\title{
Ozone pre-oxidation to the degradation technology research of MC-LR
}

\author{
Yingzi Lin ${ }^{1, a}$, Mingli Chen ${ }^{2, b}$, Jing Zhao ${ }^{2, c}$
}

\author{
${ }^{1}$ School of Municipal and Environmental Engineering institute, Jilin Jianzhu University, Changchun \\ 130118,China; \\ ${ }^{2}$ School of Municipal and Environmental Engineering institute, \\ Jilin Jianzhu University, Changchun 130118, China. \\ aLinyingzi1000@163.com, bchenmingli629@163.com, 'chhaojing4826@163.com
}

Keywords: drinking water, algae, algal toxins, removal

\begin{abstract}
Ozone pre-oxidation can effectively degrade MC-LR, 2mg / L ozone for MC-LR removal efficiency of $65.28 \%$. $2 \mathrm{mg} / \mathrm{L}$ ozone for MC-LR removal efficiency reach to $65.28 \%$. Ozone also has a better removal effect for turbidity and $\mathrm{UV}_{254}, 4 \mathrm{mg} / \mathrm{L}$ ozone for $\mathrm{UV}_{254}$ and turbidity removal efficiency are $50 \%$ and 59.38\%. But ozone removal efficiency of TOC and COD $_{\mathrm{Mn}}$ was poor, $3 \mathrm{mg} /$ L ozone for TOC and $\mathrm{COD}_{\mathrm{Mn}}$ removal rate are only $15.06 \%$ and $14.29 \%$.
\end{abstract}

\section{Introduction}

Algal toxins is a cyclic heptapeptide substance, there is a strong heat resistance ${ }^{[1]}$ and can withstand extreme $\mathrm{pH}$, natural degradation speed is very slow ${ }^{[2,3]}$.Microcystin isomers are about more than 60 kinds, which the widely distributed and the representative of microcystin (Microcystin, namely MC). Especially MC-LR, the widely distributed, and the strongest toxicity .World Health Organization (WHO) $)^{[4]}$ recommended the algal toxins in drinking water standard for MC-LR should be less than $1.0 \mu \mathrm{g} / \mathrm{L}$. Our country provides MC-LR limit of $1 \mu \mathrm{g} / \mathrm{L}$ in drinking Water Standards 2012. The study found that ozone on algal toxin has good removal effect Hengfeng Miao ${ }^{[4]}$ and other analysts believe,in the $\mathrm{O}_{3}$ : MC is $6, \mathrm{MC}$ - LR removal efficiency can reach $92 \%$,the study found that Kejia Zhang ${ }^{[5]}$, etc, the degradation of ozone in MC - LR pseudo-first-order reaction kinetics,the ozone dosing quantity increased from $0.31 \mathrm{mg} / \mathrm{L}$ to $0.31 \mathrm{mg} / \mathrm{L}, \mathrm{MC}$ - LR degradation rate increased by $0.0103 \mathrm{~min}^{-1}$ to $0.0407 \mathrm{~min}^{-1}$. The experiment mainly to study the ozone removal of MC-LR.

\section{Materials and Methods}

\section{Experimental Materials}

Experiments with water taken from a water source of raw water of the north, through the cultivation of algae.MC-LR standard solution (20ug / L) was purchased from scientific testing by the Environmental Protection Department of Agriculture. Trifluoroacetic acid (purity > 99\%) was purchased from Scharlau Company, methanol and other agents were of analytical grade.

\section{Experimental apparatus and method}

Using high performance liquid chromatography (HPLC) of Agilent 1200C for MC-LR was measured, measurement parameters: the injection volume was 20uL; UV-visible detector wavelength 238nm; column temperature was $25{ }^{\circ} \mathrm{C}$; mobile phase $0.05 \%$ TFA aqueous solution/Methanol is 45/55; the flow rate was $1.0 \mathrm{ml} / \mathrm{min}$.Application of ozone generator (3S-A3), through iodometric method to measure the concentration of ozone, Control the ozone dosing quantity is $1 \mathrm{mg} / \mathrm{L}, 2 \mathrm{mg} / \mathrm{L}, 3 \mathrm{mg} / \mathrm{L}, 4 \mathrm{mg} / \mathrm{L}, 5 \mathrm{mg} / \mathrm{L}$, the reaction time was 30min, the reaction temperature using room temperature is $25^{\circ} \mathrm{C}$, and observe the response to the phenomenon. Determination of MC - LR containing algae water quality concentration is $5.3 \mathrm{ug} / \mathrm{l}$. The TOC VCPN total organic carbon analyzer of island ferry company to measure the TOC, measurement of turbidity using HACH $2100 \mathrm{~N}$ turbidity analyzers, $\mathrm{UV}_{254}$ measured using CV-1700 UV-visible spectrophotometer. Water containing algae water quality characteristics are shown in table 1. 
Table 1 raw water quality characteristics

\begin{tabular}{|c|c|c|c|c|}
\hline $\begin{array}{c}\text { turbidity } \\
(\mathrm{NTU})\end{array}$ & $\begin{array}{c}\text { TOC } \\
(\mathrm{mg} / \mathrm{L})\end{array}$ & $\begin{array}{c}\mathrm{UV}_{254} \\
\left(\mathrm{~cm}^{-1}\right)\end{array}$ & $\begin{array}{c}\mathrm{COD}_{\mathrm{Mn}} \\
(\mathrm{mg} / \mathrm{L})\end{array}$ & $\begin{array}{c}\text { MC-LR } \\
(\mathrm{ug} / \mathrm{L})\end{array}$ \\
\hline 3.2 & 7.57 & 0.16 & 5.6 & 5.3 \\
\hline
\end{tabular}

\section{Results and Analysis}

\section{The ozone pre-oxidation for MC - LR removal}

Figure 1 shows that, ozone has good removal effect on MC - LR, with the increase of ozone dosing quantity, removal rate of MC - LR gradually strengthened. Ozone dosing $1 \mathrm{mg} / \mathrm{L}, \mathrm{MC}$ - LR removal rate was $8.11 \%$, at this point, the chroma of the water significantly reduce than raw water, analysis of the reasons may be due to ozone make the algal cells rupture and break down, resulting in decreased chroma. But the removal rate of MC - LR is low, possible reason is due to the bursting of the algal cells make intracellular toxin is released more ${ }^{[6,7]}$, lead to the removal rate of MC - LR is not obvious. Ozone dosing $2 \mathrm{mg} / \mathrm{L}$, MC - LR removal rate reached $65.28 \%$, removal rate significantly increased. $3 \mathrm{mg} / \mathrm{L}$ ozone for MC - LR removal rate reached $85.66 \%$, relative to $2 \mathrm{mg} / \mathrm{L}$ ozone, removal rate increased by $20 \%$, visible, ozone dosage exceeds $2 \mathrm{mg} / \mathrm{L}$, the removal efficiency of MC-LR showed a decreasing trend. Ozone can effectively remove the MC - LR is due MC - LR molecule contains plenty of unsaturated bond, ozone destroys the MC-LR unsaturated bonds, so as to be oxidized to become saturated small organic molecules.

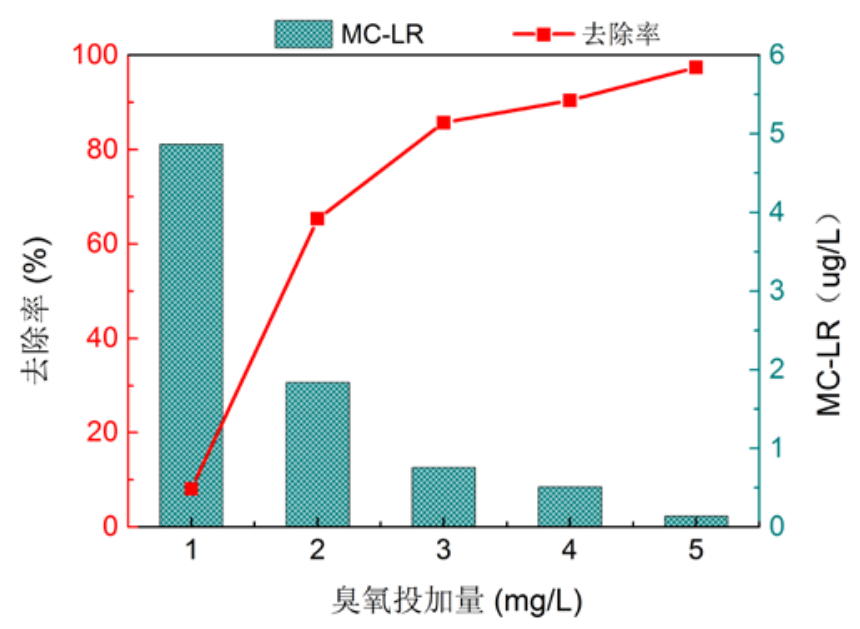

Fig. 1 Ozone pre-oxidation removal of MC-LR

The impact on other water quality characteristics of ozone pre - oxidation

The removal of turbidity and $\mathbf{U V}_{254}$

The figure 2 shows, with the increase of ozone dosing quantity, ozone pre-oxidation for $\mathrm{UV}_{254}$ and turbidity removal rate gradually enhanced, dosing $4 \mathrm{mg} / \mathrm{L}$ of ozone, turbidity and $\mathrm{UV}_{254}$ removal rate were $50 \%$ and $59.38 \%$,continue adding ozone, the growth rate of removal rate is slow. Experiments show that ozone has a certain removal capability to turbidity and $\mathrm{UV}_{254}$, but there are certain limits . 


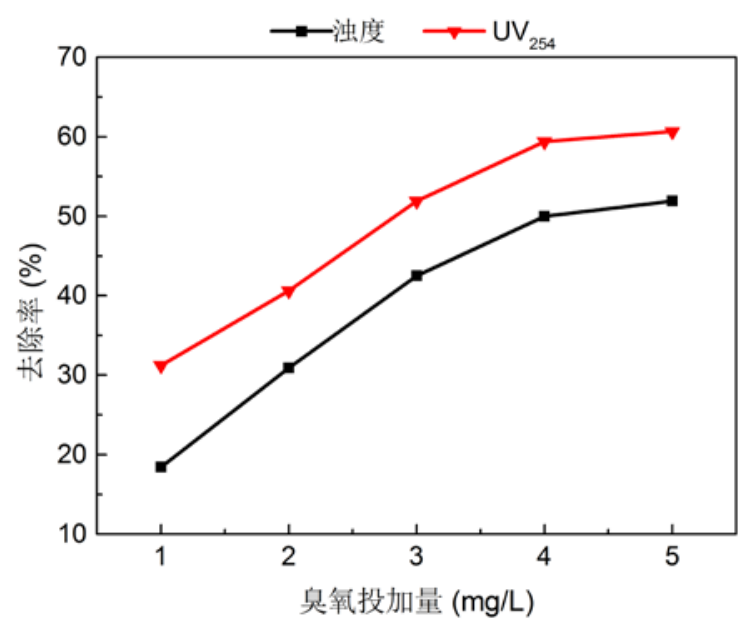

Fig.2 Ozone pre-oxidation to remove of turbidity and $\mathrm{UV}_{254}$ The removal of TOC and CODMn

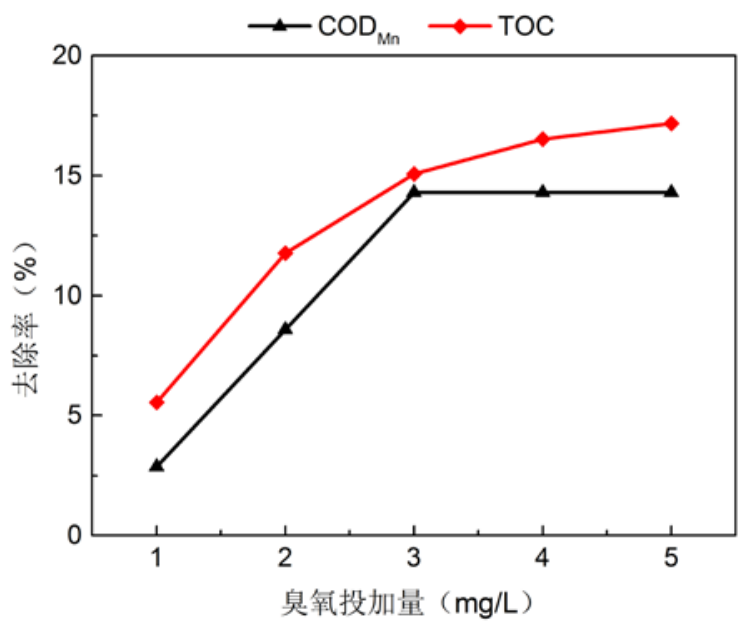

Fig. 3 Ozone pre-oxidation to removal of TOC and COD $\mathrm{Mn}$

The figure 3 shows, ozone pre - oxidation for TOC and $\mathrm{COD}_{\mathrm{Mn}}$ removal capacity is limited, 3 $\mathrm{mg} / \mathrm{L}$ ozone for TOC and $\mathrm{COD}_{\mathrm{Mn}}$ removal rate was only $15.06 \%$ and $14.29 \%$. Analysis of ozone can not effectively remove $\mathrm{COD}_{\mathrm{Mn}}$ and TOC reason is due to ozone selective oxidation ${ }^{[8]}$, ozone oxidation is mainly to change the structure and properties of organic matter, the macromolecular organic oxidation for small molecule organic matter,increase the organic matter composition with characteristics of saturated ${ }^{[9]}$, and not the complete oxidation of organic matter.

\section{Conclusion}

Ozone can effectively degrade MC-LR, when ozone dosage of 2mg / L, MC-LR removal rate reached 65.28 percent, 3mg / L ozone for MC-LR removal rate was 85.66\%, ozone can also effectively reduce turbidity and $\mathrm{UV}_{254}, 4 \mathrm{mg} / \mathrm{L}$ ozone for $\mathrm{UV}_{254}$ and turbidity removal rates are $50 \%$ and $59.38 \%$. But ozone removal efficiency of TOC and COD $_{\text {Mn }}$ was poor, $3 \mathrm{mg} / \mathrm{L}$ ozone for TOC and $\mathrm{COD}_{\mathrm{Mn}}$ removal rate are only $15.06 \%$ and $14.29 \%$.

\section{Acknowledgements}

Fund Project: the national water pollution control and governance of science and technology major projects (2012ZX07408001) . 


\section{References}

[1]Z.J.Zhou,Z.S. Xue and X.Z. Yu: Algae Toxins and Cancer. Carcinogenesis · Distortion · Mutation, Vol 9 (1997) No.6, p.335

[2] Hong-Xing S. , Jiu-Hui Q. , Ai-Min W. , Et al. : Degradation of Microcystins in Aqueous Solution with in Situ Electrogenerated Active Chlorine. Chemosphere, Vol (2005) No.60, p.326.

[3] Rivasseau C. , Martins S. , HennionM. C: Determination of some Physicochemical Parameters of Microcystins (Cyanobacterial Toxins) and Trace Level Analysis in Environmental Samples Using Liquid Chromatography. Journal of Chromatography A, Vol (1-2) (1998) No. 799, p.155.

[4] H.F. Miao, X. Lu, Q. Yan, L.J. Xie and W.Q. Ruan: Ozone Degradation Research of Microcystin Algae Toxin- LR [J].Environmental Science, Vol 30 (2009) No.11,p.3288 .

[5] K.J. Zhang, N.Y. Gao, D.D. Yin and M.H. Sui: Dynamics Research of Ozone Oxidation Degradation of Algal Ttoxins - LR [J].Journal of Tongji University (Natural Science Edition), Vol 37 (2009) No.7, p.919.

[6] H.Y. Pei, W.R. Hu: Experimental study on ozone to kill algae characteristic [J]. Industrial Water Treatment, 2003,23 (9): 55-57.

[7] CHEN J J, YEH H H.The mechanisms of potassium permanganate on algae removal [J].Wat Res, 2005, 39( 18) : 4420- 4428.

[8] P.K. Jin, X.C. Wang: Ozone oxidation characteristics of natural organic matter in water [J] . Environmental Chemistry, 2002, 21 (3): 259-263

[9] Owen D M, Amy D L, Chowdhury Z K et al., NOM Characterization and Treatability [J].J. AWWA.1995,87(1)B46)63 